\title{
Percepção dos agricultores familiares da comunidade de Roma-PB sobre o processamento mínimo de frutas e hortaliças
}

\section{Perception of family farmers of Rome-PB community on fruit and vegetables minimum processing}

\author{
Emmanuel Moreira Pereira $^{1 *}$, Vanessa Ribeiro de Lima. Fidelis ${ }^{2}$, Maria Isabel Valentim de Oliveira ${ }^{2}$ : Maria José da Silva \\ Luíz $^{2}$, Amanda Ramalho Honório de Medeiros ${ }^{2}$
}

\begin{abstract}
Resumo: O agronegócio brasileiro vem crescendo acentuadamente nos últimos anos, uma das atividades que mais se destaca nesse setor é o pequeno agronegócio, que geralmente é iniciado por famílias de comunidades rurais, como uma alternativa de fonte de renda. $\mathrm{O}$ este trabalho teve como objetivo conscientizar agricultores familiares da comunidade de Roma, município de Bananeiras-PB, com o uso da tecnologia do processamento mínimo, no intuito de agregar valor ao produto final, garantindo assim segurança alimentar, nutricional e econômica aos produtores e consumidores do Brejo Paraibano. Foi aplicado um questionário contendo 10 questões com o intuito de fazer um levantamento sobre os conhecimentos prévios e conscientização dos produtores familiares sobre o assunto, como também desenvolver a percepção dos agricultores familiares sobre o tema. No entanto, existe a necessidade de campanhas de transferência de tecnologia que possam facilitar o aprendizado e capacitação dos mesmos sobre o assunto.
\end{abstract}

Palavras-chaves: Processamento mínimo, transferência de tecnologia, produtor familiar.

\begin{abstract}
Brazilian agribusiness has grown markedly in recent years, one of the activities that stands out most in this sector is the small agribusiness, which is usually started by families of rural communities as an alternative source of income. The this study aimed to educate farmers of the community in Rome, the city of Bananeiras - PB, with the use of minimal processing technology in order to add value to the final product, thus ensuring food security, nutritional and economical for producers and consumers Brejo Paraibano. a questionnaire containing 10 questions in order to make a survey of existing knowledge and awareness of family farmers on the issue was applied, but also to develop the perception of farmers on the subject. However, there is a need for technology transfer campaigns that can facilitate the learning and training of the same on the subject.
\end{abstract}

Key words: minimal processing, technology transfer, family producer.

\footnotetext{
*Autor para correspondência

Recebido para publicação em 10/12/2015; aprovado em 23/12/2015

1*Pós-graduando em Engenharia Agrícola - UFCG/CTRN - Universidade Federal de Campina Grande, e-mail: emmanuel16mop@ @otmail.com

${ }^{2}$ Graduanda em Bacharelado em Agroindústria -UFPB/CCHSA- Universidade Federal da Paraíba
} 


\section{INTRODUÇÃO}

A agricultura familiar é um setor que ganha cada vez mais espaço no senário econômico do país, no entanto apresenta dificuldades, na parte tecnológica e agregação de valor no produto a ser comercializado.

O desafio prioritário dos setores públicos e privados, em relação ao produtor familiar, é resgatar a sua cidadania, criando condições interinstitucionais favoráveis à expansão e desenvolvimento dos produtores, de modo a enfrentar os desafios da exclusão que os vem atingindo. Para tanto, tornase necessário traçar diretrizes visando à inclusão e o desenvolvimento socioeconômico desses produtores, por meio de incentivos e ações de fomento às suas atividades, que absorvam, basicamente, mão de obra familiar.

$\mathrm{O}$ processamento mínimo de frutas e hortaliças vem ganhando espaço com a preferencia em função do seu rápido preparo e comodidade, maximizando o tempo do consumido. O processamento mínimo de uma fruta ou hortaliça resulta da sua alteração física, a partir das operações de seleção, lavagem, classificação, corte/fatiamento, sanitização, enxágue, drenagem, embalagem e refrigeração realizadas de modo a obter-se um produto fresco, sem necessidade de preparo subsequente (PUSCHMANN et al., 2006; MORETTI, 2007), comparado o produto intacto.

$\mathrm{O}$ mercado de minimamente processado adequa-se principalmente, às micro e às pequenas empresas familiares permitindo uma maior fixação de mão-de-obra no campo (DURIGAN, 2004). Ademais, os minimamente processados atingem um público seletivo e exigente que valorizam a qualidade e a segurança do alimento, geralmente, possui renda elevada e está disposto a pagar mais pela comodidade e conveniência que oferecem, pois dispensam manuseio e reduzem o tempo no preparo das refeições (NANTES E LEONELLI, 2000).

Além da agregação de valor, outra vantagem dos produtos minimamente processados é a redução nos custos de transporte em até 50\%, uma vez que as partes não comercializadas (pedúnculos e pedicelos, cascas, sementes) não são transportadas (BOLIN et al., 1977). Além de constituir produtos higienizados, prontos para o consumo.

O processamento mínimo de frutas e hortaliças sem duvidas vem como uma alternativa para o crescimento econômica, social e cultural para os agricultores familiares pertencentes à comunidade de Roma, município de Bananeiras-PB.

O objetivo deste estudo consiste em conscientizar e viabilizar a transferência do conhecimento técnico e multidisciplinar sobre o processamento mínimo de frutas e hortaliças, por meio de questionários e capacitação de recursos humanos nas associações da comunidade Roma, município de Bananeira-PB.

\section{MATERIAL E MÉTODOS}

O trabalho foi desenvolvido na comunidade de Roma, município de Bananeiras-PB, com 10 agricultores familiares que produzem de forma orgânica. Foi utilizada uma sequência didática com: A aplicação de um questionário e treinamento com o repasse da tecnologia do processamento mínimo.

O treinamento foi feito após a aplicação dos questionários no Laboratório de Pesquisa e Desenvolvimento de Produtos Frutohortícolas pertencente ao Centro de Ciências Humanas Sociais e Agrárias - Bananeiras/PB, pertencente à Universidade Federal da Paraíba. Utilizando hortaliças e frutas de produção regional.

Figura 1- Modelo de questionário proposto para a percepção dos agricultores familiares da comunidade de Roma-PB sobre o processamento mínimo de frutas e hortaliças, Bananeiras - PB, CCHSA/UFPB, 2015.

Questionário

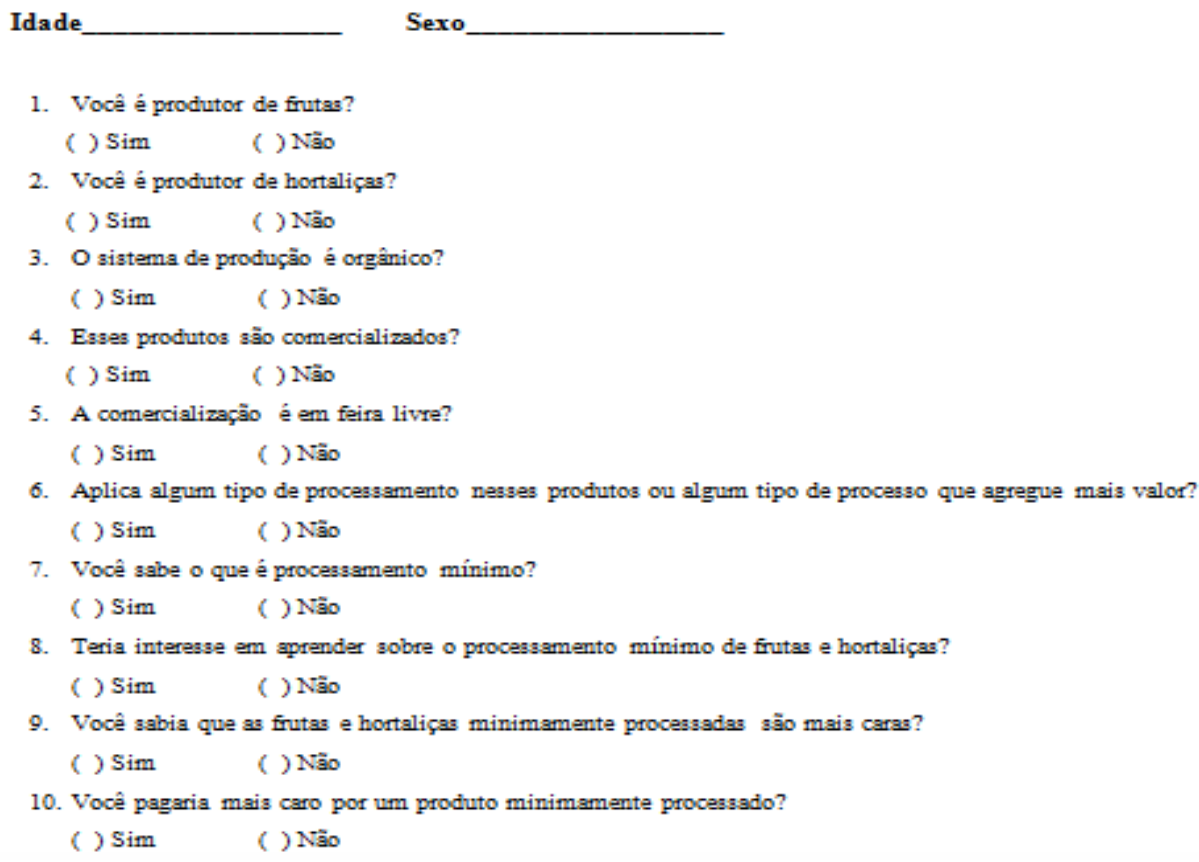




\section{RESULTADOS E DISCUSSÃO}

A sequência didática utilizada foca na percepção e capacitação, a mesma pode ser compreendida como um conjunto de atividades ligadas entre si, planejadas para ensinar um conteúdo, etapa por etapa. Organizadas de acordo com os objetivos que o professor/extensionista quer alcançar para a aprendizagem de seus alunos, elas envolvem atividades de aprendizagem e de avaliação (DOLZ, NOVERRAZ e SCNEUWLY, 2004).

Esta sequência de cunho pedagógico foi organizada e aplicada objetivando o desenvolvimento da percepção dos alunos a cerca da agregação de valor das frutas e hortaliças produzidas de forma orgânica. De acordo com Campos (2003) a palavra percepção, derivada do latim, percipere, significa apreender pelos sentidos, aprender mediante o sentido que cada coisa pode fazer na nossa vida.

A sequência didática foi aplicada da seguinte forma: a primeira atividade deste estudo foi à aplicação de um questionário com 10 questões, onde foi possível averiguar o conhecimento que os mesmos dispunham sobre o assunto.

Mediante a analise dos questionários pode ser observado, dentro do universo pesquisado algumas informações bem pertinentes ao assunto. Em seguida foram realizados treinamentos com os agricultores familiares com o repasse da tecnologia do processamento mínimo.

Quando questionado se são produtores de frutas (Figura 2), num total de $80 \%$ dos agricultores responderam que sim e apenas $20 \%$ responderão que não, esses $20 \%$ estão inclusos no percentual de produtores de hortaliças e apenas $1 \%$ não é produtor de frutas (Figura 3), ou seja, 90\% dos produtores entrevistados têm produção mista (frutas e hortaliças), caracterizados com uma produção anual, com diferentes produtos durante todo o ano.

Figura 2. Pergunta referente à caracterização dos produtores familiares em relação à produção de frutas (Você é produtor de frutas ?). A barra vertical representa o desvio padrão da média. Bananeiras - PB, CCHSA/UFPB, 2015.

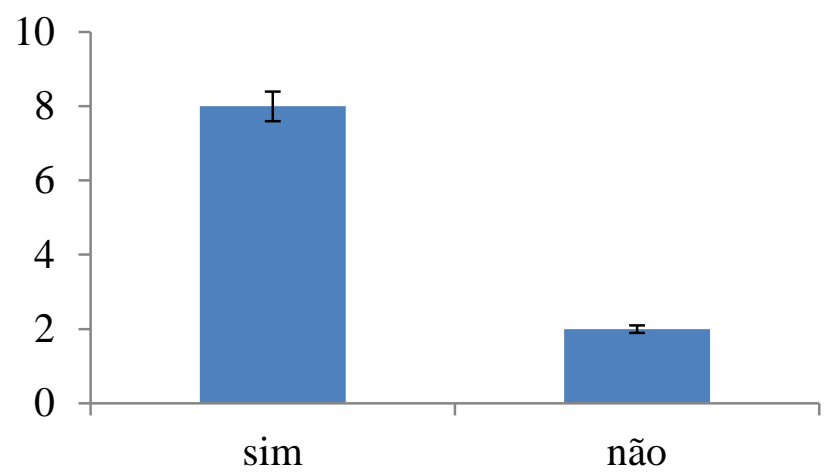

Número de produtores
Figura 3. Pergunta referente à caracterização dos produtores familiares em relação à produção de hortaliças (Você é produtor de hortaliças ?). A barra vertical representa o desvio padrão da média. Bananeiras - PB, CCHSA/UFPB, 2015.

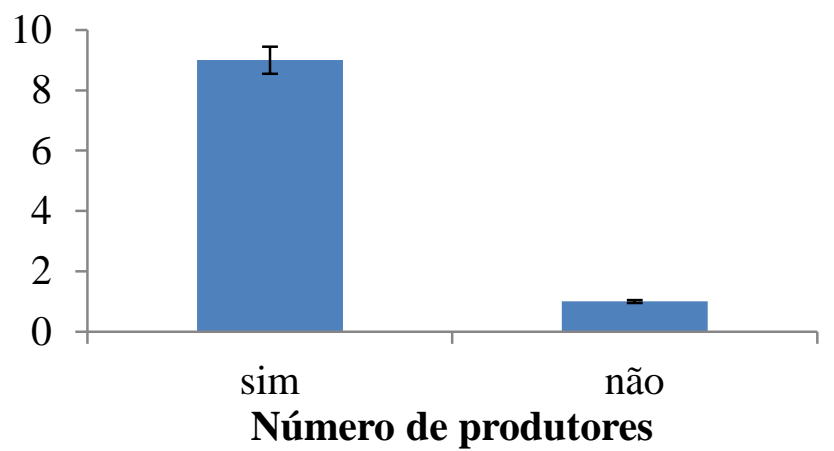

No que se diz respeito ao tipo de cultivo, $100 \%$ dos agricultores entrevistados responderam de produzem de forma orgânica (Figura 4), e que são totalmente comercializados (Figura 5).

Figura 4. Questionamento referente à caracterização dos produtores familiares em função ao sistema de produção orgânico ( $\mathrm{O}$ sistema de produção é orgânico?). A barra vertical representa o desvio padrão da média. Bananeiras PB, CCHSA/UFPB, 2015.

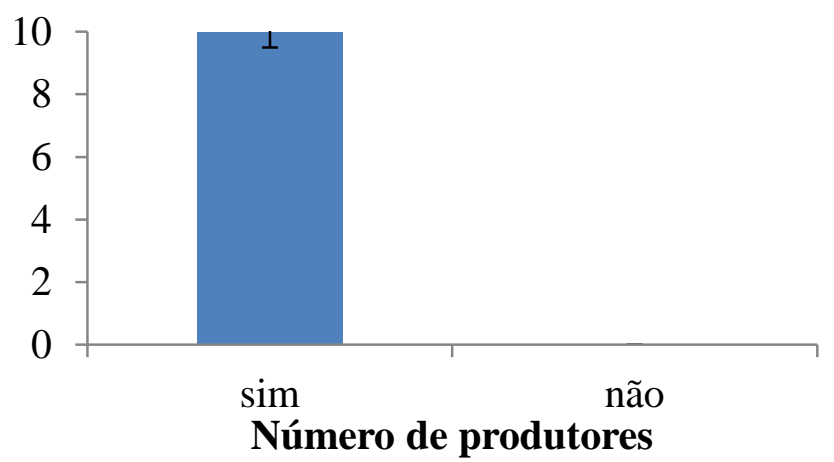

Figura 5. Questionamento referente à caracterização dos produtores familiares em função da comercialização da produção (Esses produtos são comercializados?). A barra vertical representa o desvio padrão da média. Bananeiras PB, CCHSA/UFPB, 2015.

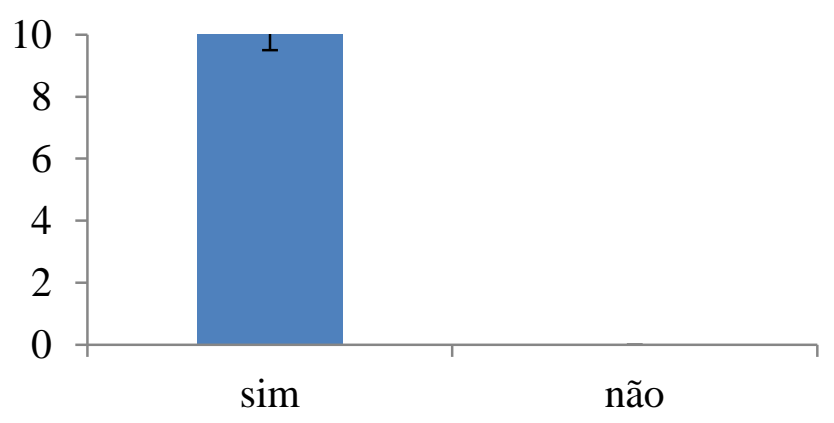

Número de produtores 
Foi questionado a respeito de como é feita essa comercialização dos produtos, e $100 \%$ dos produtores familiares responderam que é feita em feira livre (Figura 6). Levantou-se também a indagação de havia algum tipo de beneficiamento (como um pré-processamento) e apenas $20 \%$ dos entrevistados responderam que sim (Figura 7), tal fato pode ser associado ao pouco investimento do setor publico na conscientização dos produtores familiares e na agregação do valor das frutas e hortaliças.

Figura 6. Questionamento referente à caracterização dos produtores familiares em função de como é comercializado a produção (A comercialização é em feira livre ?). A barra vertical representa o desvio padrão da média. Bananeiras PB, CCHSA/UFPB, 2015.

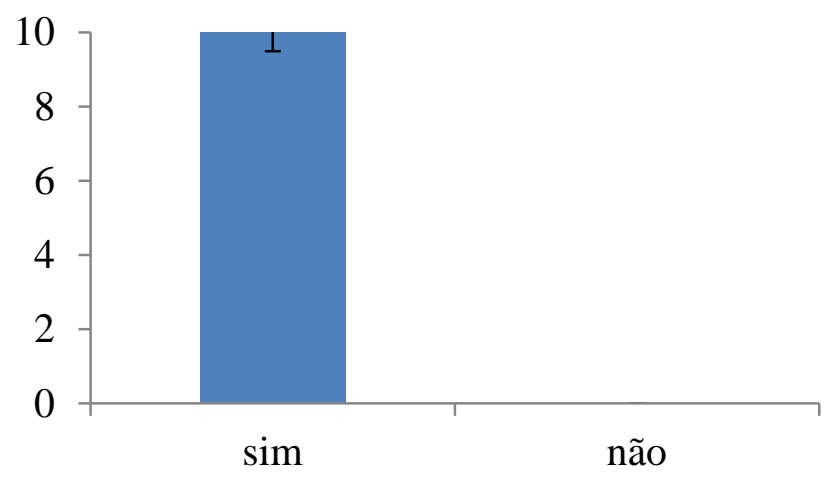

Número de produtores

Figura 7. Questionamento referente à caracterização dos produtores familiares em função beneficiamento da produção (Aplica algum tipo de processamento nesses produtos ou algum tipo de processo que agregue mais valor ?). A barra vertical representa o desvio padrão da média. Bananeiras PB, CCHSA/UFPB, 2015.

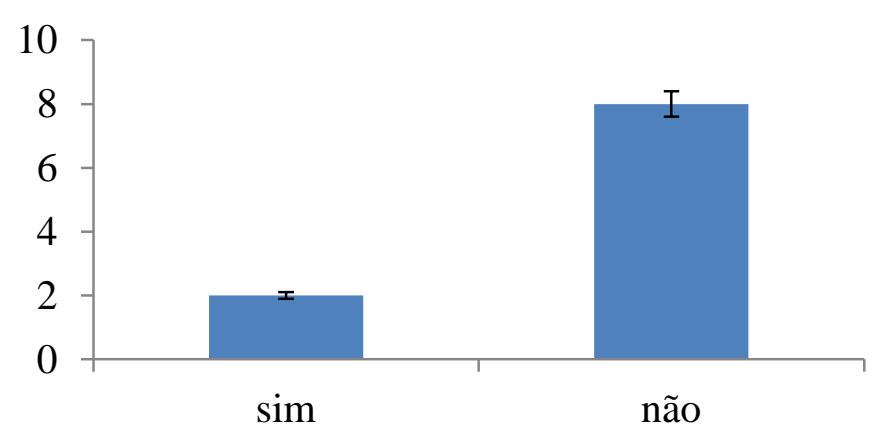

Número de produtores

Levantou-se o questionamento sobre o conhecimento do processamento mínimo de frutas e hortaliças, e apenas $20 \%$ dos entrevistados confirmaram que conhecem os produtos minimamente processados (Figura 8), os mesmos afirmaram que tem conhecimento desta técnica de agregação em função de que a comercialização de parte da sua produção é feita em feira livre na cidade de João Pessoa-PB, onde essa técnica é mais difundida. Em função desta indagação levantou-se a hipótese se os produtores se disponibilizariam em aprender a técnica do processamento mínimo de frutas e hortaliças, contudo apenas $20 \%$ dos entrevistados mostraram interesse em aprender a técnica (Figura 9), muitos alegram não ter disponibilidade de tempo, outros não mostraram interesse.

Figura 8. Questionamento referente à caracterização dos produtores familiares em do conhecimento do processamento mínimo (Você sabe o que é processamento mínimo?). A barra vertical representa o desvio padrão da média. Bananeiras PB, CCHSA/UFPB, 2015.

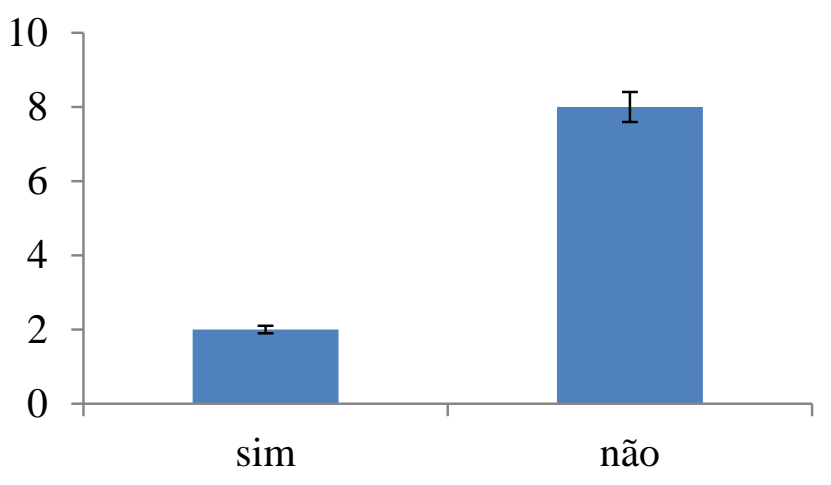

Número de produtores

Figura 9. Questionamento referente à caracterização dos produtores familiares em função do interesse no aprendizado da tecnologia do processamento mínimo (Teria interesse em aprender sobre o processamento mínimo de frutas e hortaliças ?). A barra vertical representa o desvio padrão da média. Bananeiras - PB, CCHSA/UFPB, 2015.

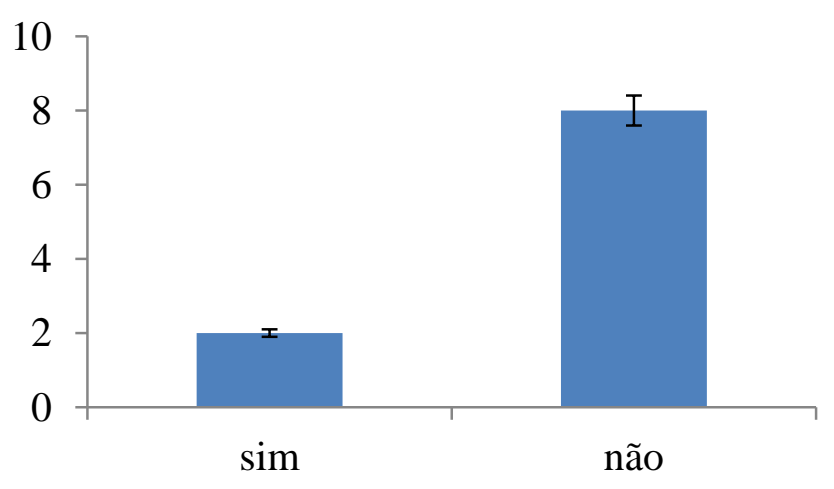

Número de produtores

Foi levantado o questionamento sobre a agregação de valor dos minimamente processados e $90 \%$ dos produtores familiares responderam que tem consciência que os minimamente são mais caros (Figura 10), esse fato pode ser atribuído ao dialogo proposto das questões anteriores, que a medida da explanação do assunto foi-se explicando o tema, assim como as vantagens que os minimamente possuem. Outro questionamento levantado foi em função da comercialização dos minimamente, se os produtores na posição de consumidores pagariam mais caro por uma fruta ou hortaliça minimamente processada, e $100 \%$ dos produtores familiares responderam que sim (Figura 11), esse aspecto pode ser atribuído ao conhecimento adquirido, além da praticidade e a higiene que os minimamente oferecem. 
Figura 10. Questionamento referente à caracterização dos produtores familiares em função do preço pago pelos produtos minimamente processados (Você sabia que as frutas e hortaliças minimamente processadas são mais caras ?). A barra vertical representa o desvio padrão da média. Bananeiras - PB, CCHSA/UFPB, 2015.

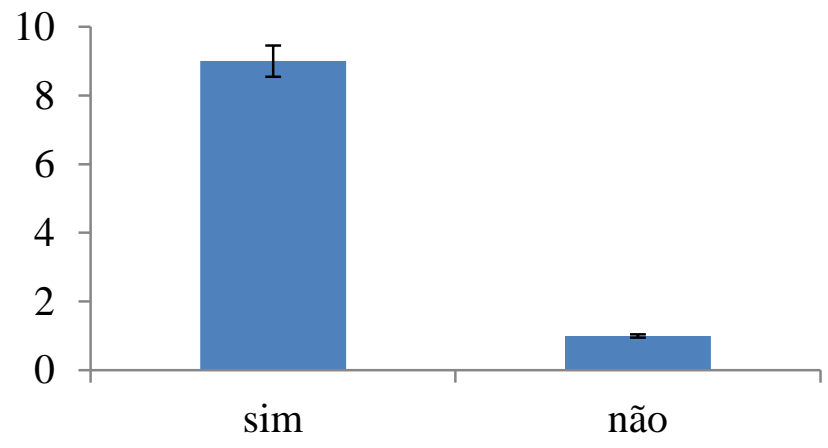

Número de produtores

Figura 11. Questionamento referente à caracterização dos produtores familiares em função do interesse de compra dos produtos minimamente processado (Você pagaria mais caro por um produto minimamente processado ?). A barra vertical representa o desvio padrão da média. Bananeiras - PB, CCHSA/UFPB, 2015.

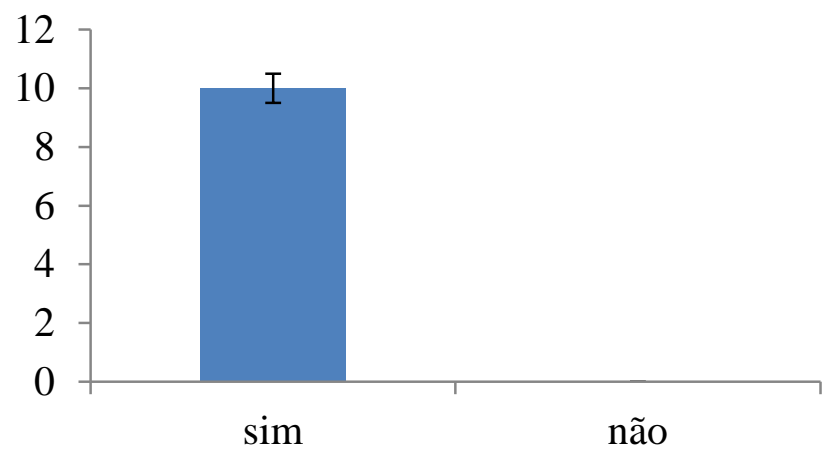

Número de produtores

O treinamento dos produtores familiares foi realizado juntamente com os discentes do curso bacharelado em agroindústria em uma feira tecnológica (EXPOTEC) ocorrido no Laboratório de Pesquisa e Desenvolvimento de Produtos Frutohortícolas pertencente ao Centro de Ciências Humanas Sociais e Agrárias- Bananeiras/PB, pertencente à Universidade Federal da Paraíba (Figura 12 a 14), resultando em um minicurso de $8 \mathrm{~h}$ com participação de 22 inscritos.

Figura 12. Aula teórica sobre as tendências, etapas e importância do processamento mínimo de frutas e hortaliças. Bananeiras - PB, CCHSA/UFPB, 2015.

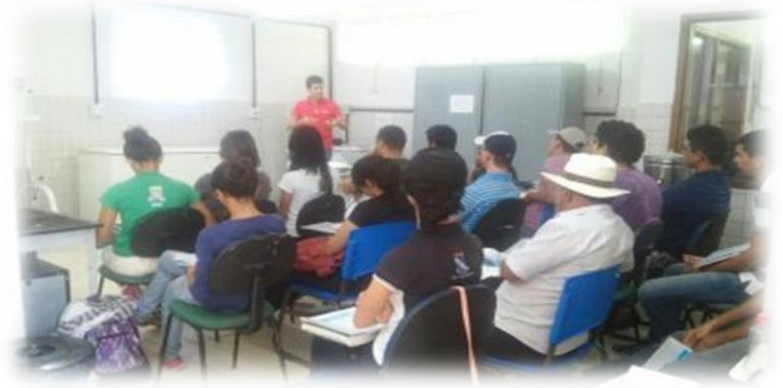

Figura 13. Treinamento com hortaliças e frutas minimente processadas. Bananeiras - PB, CCHSA/UFPB, 2015.

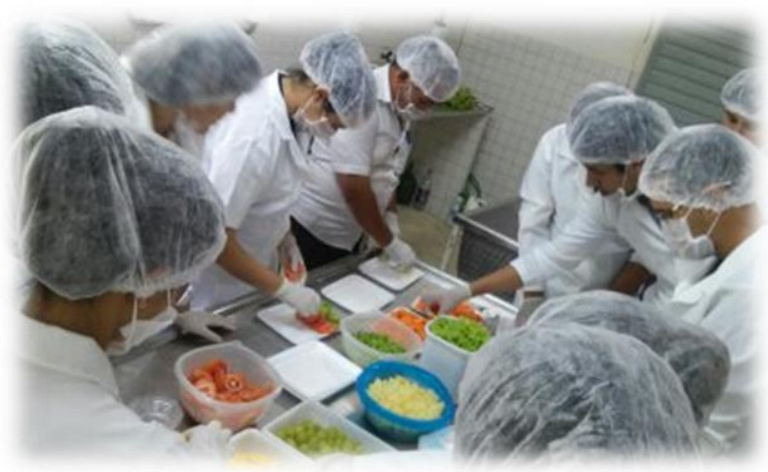

Figura 14. Treinamento com hortaliças e frutas minimente processadas. Bananeiras - PB, CCHSA/UFPB, 2015.

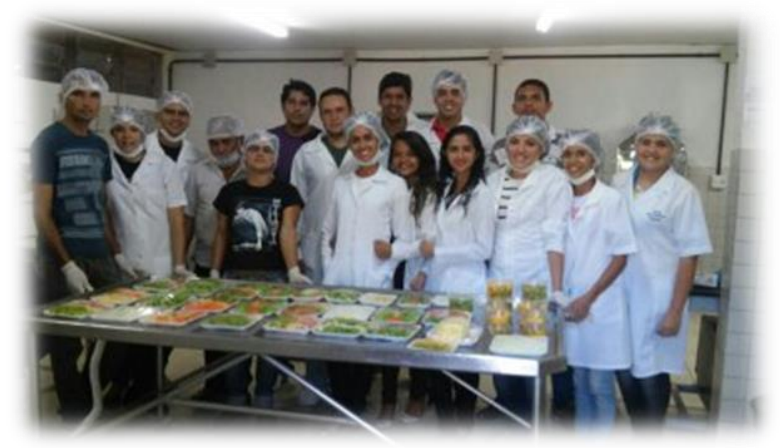

\section{CONCLUSÕES}

Ao final do treinamento observou-se que este trabalho despertou entusiasmo e interesse dos produtores rurais e jovens estudantes com a visão de agregar valor com qualidade o fruto e hortaliças, pensando na praticidade e inovação para o desenvolvimento de sua comunidade;

Além de sinaliza a suma importância das universidades vinculadas com o campo, levando conhecimentos tecnológicos para a construção da sustentabilidade de propriedades pequenas e de modo de vida da agricultura familiar, promovendo a elevação do desenvolvimento socioeconômico rural.

Existindo a necessidade de campanhas de transferência de tecnologia que possam facilitar o aprendizado e capacitação dos mesmos sobre o assunto.

\section{REFERÊNCIAS BIBLIOGRÁFICAS}

BOLIN, H.R.; STAFFORD, A.D.; KING JR., A.D. e HUXSOLL, C.C. Factors affecting the storage stability of shredded lettuce. Journal of Food Science. 42, 1319-1321, 1977.

CAMPOS, N; STUDART, T. Gestão de Águas: princípios e práticas. 2. Ed./ Editado por Nilson Campos e Ticiana Studart. Porto Alegre: ABRH, 2003. 242p.

DOLZ, NOVERRAZ e SCNEUWLY. Sequências didáticas para o oral e a escrita: apresentação de um procedimento. In. DOLZ \& SHNEUWULY (orgs) Gêneros Orais e Escritos na Escola. São Paulo: Mercado de Letras, 2004. 
DURIGAN, J.F. Processamento mínimo de frutas e hortaliças. Fortaleza: Instituto Frutal, 69 p., 2004.

MORETTI CL. 2007. Laboratório de pós-colheita, Embrapa hortaliças. Disponível em: <www.cnph.embrapa.br/public/textos/texto7.html> Acesso em: Dezembro de 2015.

NANTES, J.F.D.; LEONELLI, F.C.V. A estruturação da cadeia produtiva de vegetais minimamente processados. Revista FAE. 3, 61-69, 2000.
PUSCHMANN R; COSTA FB; SIMÕES AN; SILVA EO. 2006. História e atualidades sobre pesquisa com processamento mínimo de frutas e hortaliças no Brasil. In: ENCONTRO NACIONAL SOBRE PROCESSAMENTO MÍNIMO DE FRUTOS E HORTALIÇAS, 9 SIMPÓSIO IBERO-AMERICANO DE VEGETAIS FRESCOS E CORTADOS,1. Resumos... São Pedro: USP/ESALQ.. 